Case Report

\title{
An unusual presentation of a granulosa cell tumor in broad ligament: morphological features and close differential
}

\author{
Singh A. ${ }^{1}$, Singh V. ${ }^{2}$, Bhargava M. ${ }^{3}$, Kumar M. ${ }^{4}$, Singh A. ${ }^{5}$, Satyam $^{6}$, Misra V. ${ }^{7}$ \\ ${ }^{1}$ Dr. Anshul Singh, Associate Professor, ${ }^{2}$ Dr. Vasudha Singh, IIIrd Year Resident, ${ }^{3}$ Dr. Mudita Bhargava, IIIrd Year \\ Resident, ${ }^{4}$ Dr. Manoj Kumar, IIIrd Year Resident, ${ }^{5}$ Dr. Akhilesh Singh, IIIrd Year Resident, ${ }^{6}$ Dr. Satyam, IIIrd Year \\ Resident, ${ }^{7}$ Dr. Vatsala Misra, Professor and H.O.D, all authors are affiliated with Department of Pathology, M.L.N. \\ Medical College, Prayagraj (U.P.) India.
}

Corresponding Author: Dr. Anshul Singh, Associate Professor, Department of Pathology, M.L.N. Medical College, George Town, Prayagraj, E-mail: anshul.sjh@gmail.com

\begin{abstract}
Background: Though Granulosa cell tumors (GCTs) are the most common ovarian sex cord stromal tumors, they are very rare in extra ovarian sites with a handful of cases reported in retroperitoneum, broad ligament, fallopian tube, mesentery and even in the adrenals. Female Adnexal Tumor of probable Wolffian Origin (FATWO), which is also a very rare tumor comes up as its closest differential because of a significant overlap of topographic, morphologic, and immunohistochemical (IHC) features. Case Summary: Present case is of a post-menopausal female who complained of abdominal swelling and post-menopausal bleeding. On CT, she was shown to have a broad ligament mass (fibroid) which was excised. On histopathological reporting the tumor showed mainly the lesser known morphological variants of GCT that lead to difficulty in reaching at the exact diagnosis and a differential of an extraovarian GCT [eGCT] vs. FATWO was given which on IHC finally turned out to be an eGCT. Conclusion: Broad ligament is the site of two very rare tumors of the female genital tract, i.e. eGCT and FATWO which are close mimickers of each other not only on topography, but also on morphology and immunohistochemistry. Hence distinguishing between these two entities may be quite challenging for a pathologist, but aid of certain features can be taken to arrive at the diagnosis many a times.
\end{abstract}

Keywords- Extraovarian, FATWO, Sex cord stromal tumors

\section{Introduction}

Though ovarian granulosa cell tumors are not an infrequent finding, extraovarian granulosa cell tumors (eGCT) are very uncommon, assumed to arise from the ectopic gonadal tissue along the embryonal route of the genital ridge. It is noteworthy that a diagnosis of eGCT should be carried out only after excluding any previous history of GCT of the ovary [1]. Amongst all the cases published so far, most of the eGCTs have been reported in various parts of the retroperitoneum [2-8], followed by broad ligament [9-11], fallopian tube [12, 13], mesentery [14] and even adrenals [15]. Interestingly, eGCTs share a significant overlap topographically, morphologically, and immunohistochemically with another very rare tumor, Female Adnexal Tumor of probable Wolffian Origin (FATWO), which comes across as its closest differential [9, 10], especially amongst the broad ligament tumors. This can be quite troublesome for the reporting pathologist many a times, especially when the predominant pattern is diffuse proliferation / trabecular/ gyriform. The present case report was a case of a post-menopausal female with a broad ligament mass where a very unusual morphology of granulosa cell tumor and enumerate the points that helped us arrive at the correct diagnosis.

\section{Case Report}

A 58-year female presented to the surgery O.P.D. of our institute with pain and swelling in the abdomen since 8 months. She also complained of postmenopausal bleeding. There was no any other significant past history or treatment history. Her CBC parameters were in normal range and her CA-125 was $693 \mathrm{U} / \mathrm{mL}$. She was advised CT of the abdomino pelvic region that was reported as a broad ligament fibroid [Figure 1a]. She underwent surgical excision of the tumor mass along with pan-hysterectomy that was sent to our department for histopathological examination.

Manuscript received: $30^{\text {th }}$ August 2019

Reviewed: $10^{\text {th }}$ September 2019

Author Corrected: $18^{\text {th }}$ September 2019

Accepted for Publication: $23^{\text {rd }}$ September 2019

Pathology Update: Tropical Journal of Pathology \& Microbiology Available online at: www.medresearch.in 740 | P a g e 
The specimen was received in two labelled vials.

\section{Case Report}

Specimen-1 was a total hysterectomy with unilateral salpingo-oophorectomy, where the entire uterus with cervix measured $10 \times 5 \times 2 \mathrm{~cm}$ in size. On cutting uterine wall thickness was $2.5 \mathrm{~cm}$ with regular endometrial as well as regular endocervical canal. One section from endometrium with myometrium and two sections from cervix were taken and processed. Fallopian tube measured $3.1 \mathrm{~cm}$ in length. On cutting tube lumen was obliterated. Same sided ovary measured $1.2 \times 1 \mathrm{~cm}$ in size. Cut section was homogeneous grey white. One section each from both the tube and ovary were taken and processed.

Specimen 2 was a single, globular, encapsulated paratubal (broad ligament) mass showing prominent surface vessels with attached fallopian tube and ovary measuring $11 \times 8 \times 5 \mathrm{~cm}$ in size. On cutting through the mass, variegated haemorrhagic solid and cystic areas were seen. Twelve sections from various areas of the mass were taken and processed [Figure $1 \mathrm{~b}, \mathrm{c}, \mathrm{d}$ ]. Fallopian tube measured $3 \mathrm{~cm}$ in length. On cutting tube lumen was obliterated. Same sided ovary measured $1 \times 1 \mathrm{~cm}$ in size. Cut section was homogeneous grey white. One section each from both the tube and ovary were taken and processed.

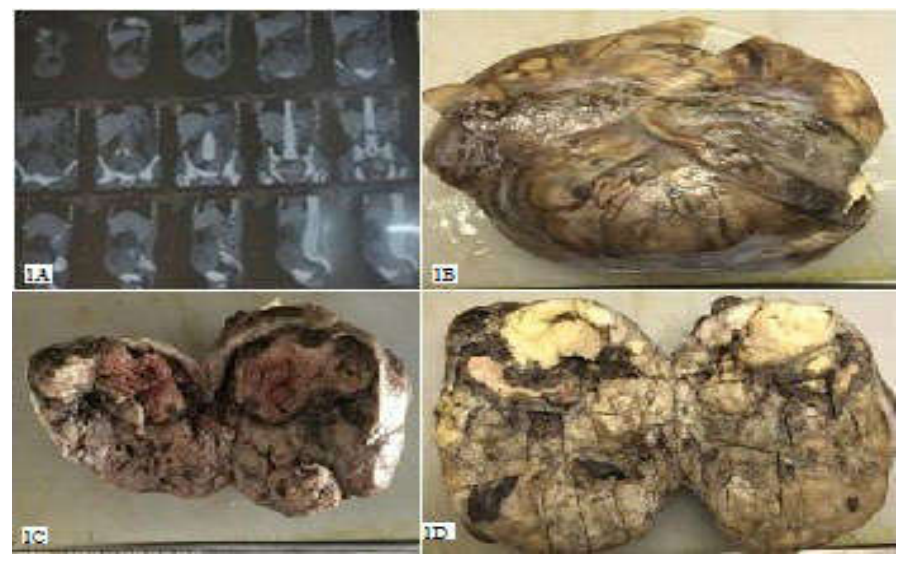

Figure-1: 1a: CT film showing the huge pelvic tumor; $1 \mathrm{~b}$ : Gross of the tumor mass which is bosselated, encapsulated and with prominent surface vessels; $1 \mathrm{c}$ : Cut surface of the tumor showing some haemorrhagic and cystic areas; 1d: Cut surface of the tumor showing some greyish brown to greyish white solid areas On microscopy, the panhysterectomy specimen was unremarkable. Sections examined from various areas of broad ligament mass showed an encapsulated tumour with multiple patterns. Predominant pattern was diffuse solid proliferation along with minor components of microcystic, trabecular and gyriform patterns. No well-formed tubules were seen anywhere. The tumour cells were mainly spindled along with few epithelioid forms, neither of which showed any significant pleomorphism, had a vesicular nucleus with prominent nucleoli and moderate amount of mostly clear cytoplasm. Occasional areas showed nuclear grooving also [Figure 2a-f]. Some of the sections show very prominent vascular proliferation. Mitotic activity was low. No necrosis was seen anywhere.

Microscopic findings were consistent with a low-grade neoplastic lesion. Two differentials were considered: -

1. Broad ligament Granulosa cell tumor 2. Female adnexal tumour of wolffian origin

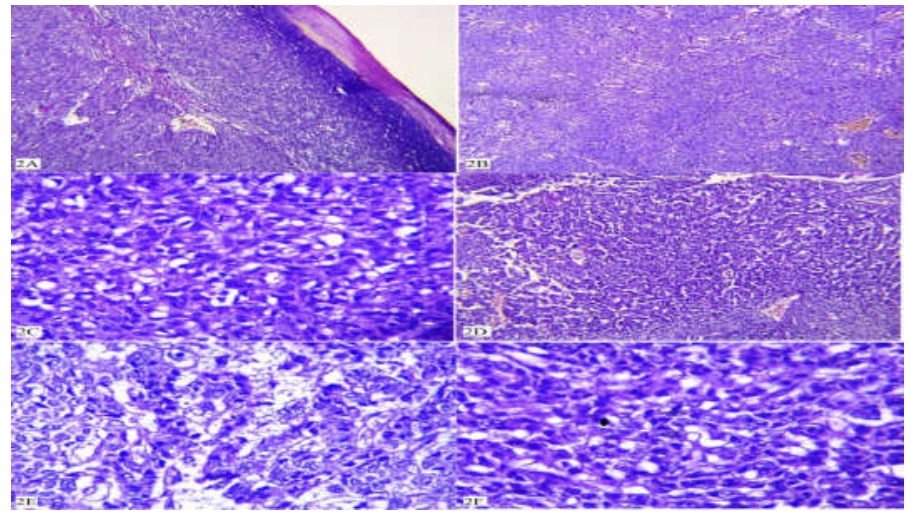

Figure 2- 2a: Scanner view showing a well encapsulated tumor area [H and E X 4x]; 2b: Spindled tumor cells showing diffuse growth pattern [Hand E X10x] ; 2c: Epithelioid tumor cells showing diffuse growth pattern [Hand E X10x]; 2d: 


\section{Case Report}

Focal areas showing gyriform pattern of growth [Hand E X10x]; 2e: Cells with prominent nucleoli and moderate amount of mostly clear cytoplasm [Hand E X 40x]; 2f: Few nuclear grooves(arrows) [Hand E X 40x]

IHC for CK7, Inhibin and Calretinin was advised for confirmation where the former was negative and the latter two were focally positive, thus making this case to be an extraovarian (Broad Ligament) Granulosa cell tumor [Figure 3a and b]

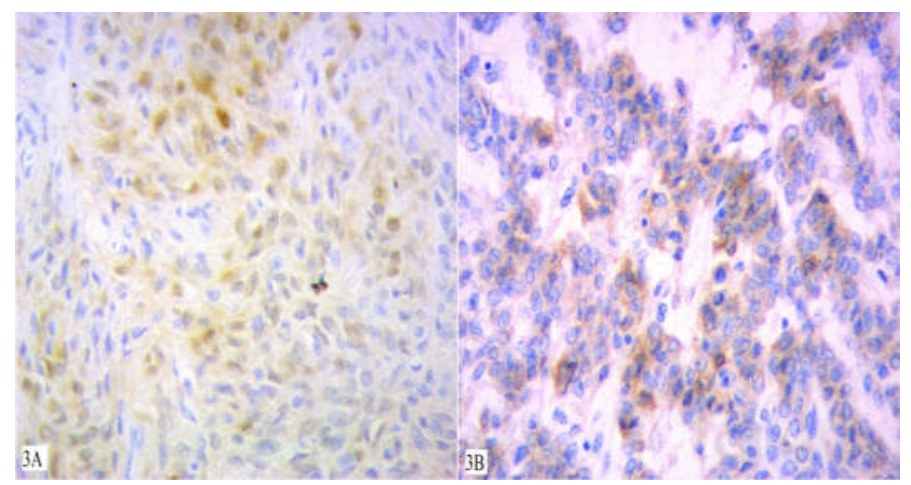

Figure 3- 3a: Focal positivity for Calretinin [IHCX40x]; 3b: Focal positivity for Inhibin [IHCX40x]

\section{Discussion}

The World Health Organization (WHO) defines granulosa cell tumor (GCT) as a neoplasm composed of a pure or at the least a $10 \%$ population of granulosa cells, often in a fibrotheromatous background. GCTs account for about $1.5 \%-5 \%$ of all ovarian tumors and occur in a wide age range, from newborn to postmenopausal women. Two major subtypes are recognized, an adult and a juvenile type.

Adult granulosa cell tumors (AGCTs) are the most common sex cord-stromal tumors, occur more often in postmenopausal women, with a peak incidence between 50 and 55 years. Grossly, they vary from tiny lesions to huge masses filling the abdomen, with bilateral occurrence seen in only $2 \%$.

The external surface may be smooth or bosselated. The cut surface is solid, partly solid and partly cystic, or rarely, entirely cystic. The cystic spaces may contain proteinaceous fluid or old altered blood. Hemorrhage and necrosis are common.

On microscopy, Granulosa cells are small, usually round to polygonal, but may be spindle-shaped with scanty amphophilic cytoplasm and having indistinct cell borders. Their round, oval or angular nuclei often show a deep longitudinal groove and may exhibit a small, variably prominent nucleolus. The nuclear chromatin may be compact and dense or loose and vesicular.

The tumor cells grow in a variety of patterns, including microfollicular (call exner bodies seen in 30-50\%), macrofollicular, trabecular, insular, tubular and the rarer diffuse, moiré silk, and gyriform patterns.
In recent karyotypic and fluorescence in situ hybridization analyses, it has been shown that trisomy 12 is not that common in granulosa cell tumor as was thought previously. Rather a single, recurrent somatic mutation $(402 \mathrm{C} \rightarrow \mathrm{G})$ in FOXL2 gene has been identified in a large proportion of AGCTs studied and is used to distinguish AGCT from both non - sex cordstromal tumors and other tumors in the sex cord-stromal category $[1,16]$.

Extraovarian granulosa cell tumor (e GCTs) are very uncommon tumors. Amongst all the cases published so far, most of the eGCTs have been reported in various parts in the retroperitoneum [2-8], followed by broad ligament [9-11], fallopian tube [12, 13], mesentery [14] and even adrenals [15].

The histogenesis of paratubal GCT in the broad ligament is unknown but it is postulated that as in uterine sex cord stromal tumor, these neoplasms may also be derived from multipotential cells within the broad ligament or possibly from ectopic gonadal stromal tissue [16].

All granulosa cell tumors have a malignant potential, with the capacity to extend beyond the ovary or recur after surgical removal; because broad ligament GCTs are very rare, it is not possible to determine their prognosis, though some studies suggest that they may be more aggressive than their ovarian counterparts [9].

Female adnexal tumor of probable Wolffian origin (FATWOs) are an exceptionally rare neoplasm of low grade malignant potential originating from the Wolffian ductal system. They have been reported in the broad 


\section{Case Report}

ligament, mesosalpinx and ovarian hilum in females with a wide age range (15-72 years). [17-20] They are characterised by a wide variety of histological patterns, some of which closely simulate other pelvic tumors. The diagnosis of FATWO is based mainly on its topography and its morphologic appearance of a sievelike retiform pattern of hollow tubules and cysts, closely packed tubules, and diffuse solid sheets of cells. It may also sometimes show the gyriform and trabecular pattern similar to that of GCTs $[1,11]$. Since in our case the predominant pattern was diffuse along with areas of trabecular and gyriform pattern, we had a problem in making a definitive diagnosis on histopathology alone and so both an eGCT and FATWO were suggested as the differentials.

In addition to morphologic similarities of GCT and FATWO, the basic immunophenotype of FATWO is also quite similar. Like GCTs, they also show positivity for Inhibin, Calretinin, pan CK, CAM 5.2, and are negative for EMA. But FATWOs are always positive for CK 7 and generally negative for FOXL2 which comes to the rescue of a pathologist in differentiating it from an eGCT $[3,4]$.

Additionally, on molecular analysis, FATWOs never show FOXL2 mutation which is always present in a GCT [16]. Hence, we too went ahead with an IHC panel of CK7, Inhibin and Calretinin to arrive at the exact diagnosis.

As recommended by Czernobilsky et al, nuclear grooving, though not an exclusive feature of GCT, in the context of the differential diagnosis between broad ligament GCT and FATWO, the presence of this feature may be very useful in establishing the diagnosis of broad ligament GCT [9]. In our case too, we found nuclear grooving in some of the areas.

\section{Conclusion}

Though both Granulosa cell tumor and Female adnexal tumor of wolffian origin are very rare tumors reported in the broad ligament, a pathologist should be aware of both these entities which are very close mimickers of each other.

This is especially important when the predominant pattern is diffuse proliferation / trabecular/ gyriform. Extensive sampling and careful search for certain features on morphology like presence of even focal areas of nuclear grooving, absence of sieve-like pattern and a negative immunostain for $\mathrm{CK}-7$ helps in establishing a diagnosis of an extraovarian Granulosa cell tumor.
Acknowledgement: Dr. Santosh Singh, Department of Surgery, M.L.N. Medical College, Prayagraj for providing us this case.

Findings: Nil; Conflict of Interest: None initiated Permission from IRB: Yes

\section{References}

1. Sarah Chaing, Philip B. Clement, Robert H. Young. Fallopian Tube and Broad Ligament. Sternberg's diagnostic surgical Pathology; $6^{\text {th }}$ Ed. 2:2664

2. Paul PC, Chakraborty J, Chakrabarti S, Chattopadhyay B. Extraovarian granulosa cell tumor. Indian J Pathol Microbiol. 2009;52(2):231-233.

3. Neeli SI, Malur PR. Primary retroperitoneal extraovarian granulosa cell tumor: A case report. Uro Today Int J. 2010;3(6):1. doi:10.3834/uij.1944-5784. 2010.12 .14

4. Al-Shraideh Y, Mahfooz AB, Moazin M, Aslam M, Alhazmi A, Alshakweer W. Primary Retroperitoneal Granulosa Cell Tumor. Uro Today Int J. 2012;5(6): art61.doi:http://dx.doi.org/10.3834/uij.1944-5784.2012. 12.11

5. Abuseini A, Al-Kaisi N. Extra-Ovarian Granulosa Cell Tumor: A Case Report. J Royal Med Serv. 2014;102(1326):1-3.

6. Medhi P, Dowerah S. A Rare Case of Extraovarian Granulosa Cell Tumor Presenting as a Retroperitoneal Mass. Ann Pathol Lab Med. 2016;3(03).

7. Saad Rifki Jai, Robleh Hassan Farah, Adil Boussabir, Rachid Boufettal, Farid Chehab. Extraovarian granulosa cell tumor: a case report. Pan African Med J. 2016; 23:86. doi: doi: 10.11604/ pamj. 2016. 23. 86. 8048

8. Vasu PP, Leelamma JP, Mohammed BA, Yesodharan J. Primary granulosa cell tumor of retroperitoneal origin: A rare presentation with emphasis on cytomorphology. J Cytol/ Indian Acad Cytolog. 2016;33(1):52.

9. Czernobilsky B, Lifschitz-Mercer B, Trejo L, Atlas I. Granulosa cell tumor of the broad ligament: report of a case with emphasis on the differential diagnosis with female adnexal tumor of probable Wolffian origin. Int $\mathrm{J}$ Surg Pathol. 2011;19(6):783-786. doi: 10.1177/1066 896 909356104. Epub 2009 Dec 29. 


\section{Case Report}

10. Wang J, Grant M, Patel V, Abir M. An Unusual Case of Broad Ligament Malignant Tumor: Differential Diagnosis of Female Adnexal Tumor of Probable Wolffian Origin and Extraovarian Granulosa Cell Tumor. Am J Clinic Pathol. 2015;144(suppl_2):A263. doi: https: //doi.org/ 10.1093/ ajcp/144. suppl2. 263

11. Omori M, Kondo T, Fukushima J, Oi M, Watanabe Y, Nakazawa T, et al. Extraovarian Fibroma With Minor Sex Cord Elements: A Case Report and Literature Review. Int J Surg Pathol. 2017;25(5):472476. doi: 10.1177/1066896917700727. Epub 2017 Mar 28.

12. Sakkas EG, Bucella D, De Wind AR, Stanciu C, Buxant F. Atypical presentation and localization of granulosa cell tumor: A case report and review of the literature. Open J Obstet Gynecol. 2012;2(02):161-163. doi: http://dx.doi.org/10.4236/ojog.2012.22031

13. Barbosa LC, Campos FS, Archangelo SD, Francisco AM. Extraovarian Granulosa Cell Tumor of Fallopian Tube: A Case Report. J Minimal Invas Gynecol. 2013; 20(6): S159. doi:doi.org/10.1016/j.jmig.2013.08.536.

14. Naniwadekar MR, Patil NJ. Extraovarian granulosa cell tumor of mesentery: A case report. Pathology research international. 2010;2010. doi:http://dx.doi. org/10.4061/ 2010/292606
15. Hameed A, Coleman RL. Fine needle aspiration cytology of primary granulose cell tumor of the adrenal gland:a case report. Diagn Cytopathol 2000;22(2)P: 107-109. doi: https://doi.org/10.1002/ (SICI)10970339(200002)22:2<107::AID-DC10>3.0. CO;2-1

16. Robert J. Kurman, Maria Luisa Carcangiu, C. Simon Herrington, Robert H. Young, (Eds): WHO Classification of Tumours of Female Reproductive Organs. 2014 IARC:Lyon;France

17. Gupta AK, Srinivasan R, Nijhawan R. Female adnexal tumor of probable Wolffian origin. Indian $\mathrm{J}$ Pathol Microbiol. 2014;57(4):620-622. doi: 10.4103/ 0377-4929.142703.

18. Syriac S, Durie N, Kesterson J, Lele S, MhawechFauceglia P. Female adnexal tumor of probable Wolffian origin (FATWO) with recurrence 3 years postsurgery. Int J Gynecol Pathol. 2011;30(3):231-235. doi: 10.1097/PGP.0b013e3182005340.

19. Yu N, Zhao D, Liu Y, Zhang T. Wolffian tumor: report of five cases and review of literature. Int J Clin Exp Pathol 2017;10(3):3558-3564.

20. Bal H, Agrawal SA, Kumar H, Shokeen V. Female adnexal tumor of Wolffian origin: Case report of a rare tumor. Med J Dr. DY Patil Vidyapeeth. 2018;11(6): 562-564. doi: 10.4103/mjdrdypu.mjdrdypu_71_18

\section{How to cite this article?}

Singh A, Singh V, Bhargava M, Kumar M, Singh A, Satyam, Misra V. An unusual presentation of a granulosa cell tumor in broad ligament: morphological features and close differential. Trop J Path Micro 2019;5(9):740-744.doi:10. 17511/jopm.2019.i09.20. 